\title{
Opportunistic Nocturnal Predation by a Diurnal Snake: An Indian Ratsnake, Ptyas mucosa (Linnaeus 1758), Preying on Marbled Balloon Frogs (Uperodon systoma)
}

\author{
Avrajjal Ghosh ${ }^{1,2}$, Shweta Madgulkar ${ }^{2}$, and Krishnendu Banerjee ${ }^{2,3}$
}

${ }^{1}$ School of Biological Sciences, National Institute of Science Education and Research, Bhubaneshwar, Odisha-752050, India (avrajjal.ghosh@niser.ac.in) ${ }^{2}$ Department of Ecology and Environmental Sciences, School of Life Sciences, Pondicherry University, Puducherry-605104, India (shwetamadgulkar@gmail.com)

${ }^{3}$ Endangered Species Management Department, Wildlife Institute of India, Chandrabani, Dehradun, Uttarakhand-248001, India (krishabd007@gmail.com)

A nimal species have evolved specific diel cycles depending on the relative costs and benefits of activity at various times. Animals are generally diurnal, crepuscular, or nocturnal and most deviations from those patterns are minor (Metcalfe et al. 1998, DeGregorio et al. 2014). However, more drastic shifts (i.e., from diurnal to nocturnal or vice-versa) have been observed (e.g., Oishi et al. 2004). Observations of nocturnal foraging activity have been recorded in diurnal snakes such as the Western Ratsnake (Pantherophis obsoletus) in North America, Buff-striped Keelback (Amphiesma stolatum) from Sri Lanka, and the Dice Snake (Natrix tessellata) from the Mediterranean island of Crete (Sperry et al. 2013; Mebert et al. 2011; Dissanayake and Wellappuliarachchi 2016; DeGregorio et al. 2014). Such behavior in Indian serpents has been reported in the Indian Ratsnake (Ptyas mucosa) and the Buff-striped Keelback (Amphiesma stolatum) (Chaudhuri et al. 2018; Dutta et al. 2017). Herein we report a second instance of nocturnal feeding behavior by an Indian Ratsnake (Ptyas mucosa) from the Pondicherry University Campus, Puducherry, India $\left(12.033435^{\circ} \mathrm{N} 79.859844^{\circ} \mathrm{E}\right)$.

The Indian Ratsnake is a predominantly diurnal snake distributed widely from eastern Iran, Turkmenistan, and the Indian Subcontinent (including the Andaman Archipelago) to peninsular Malaysia, including Taiwan, Sumatra, Java, and southern China (Das 2010). It inhabits a wide range of habitats including forests and urbanized landscapes from sea level to $4,000 \mathrm{~m}$ asl (Das 2010). It is known to feed on a variety of prey, including amphibians, birds, small mammals,
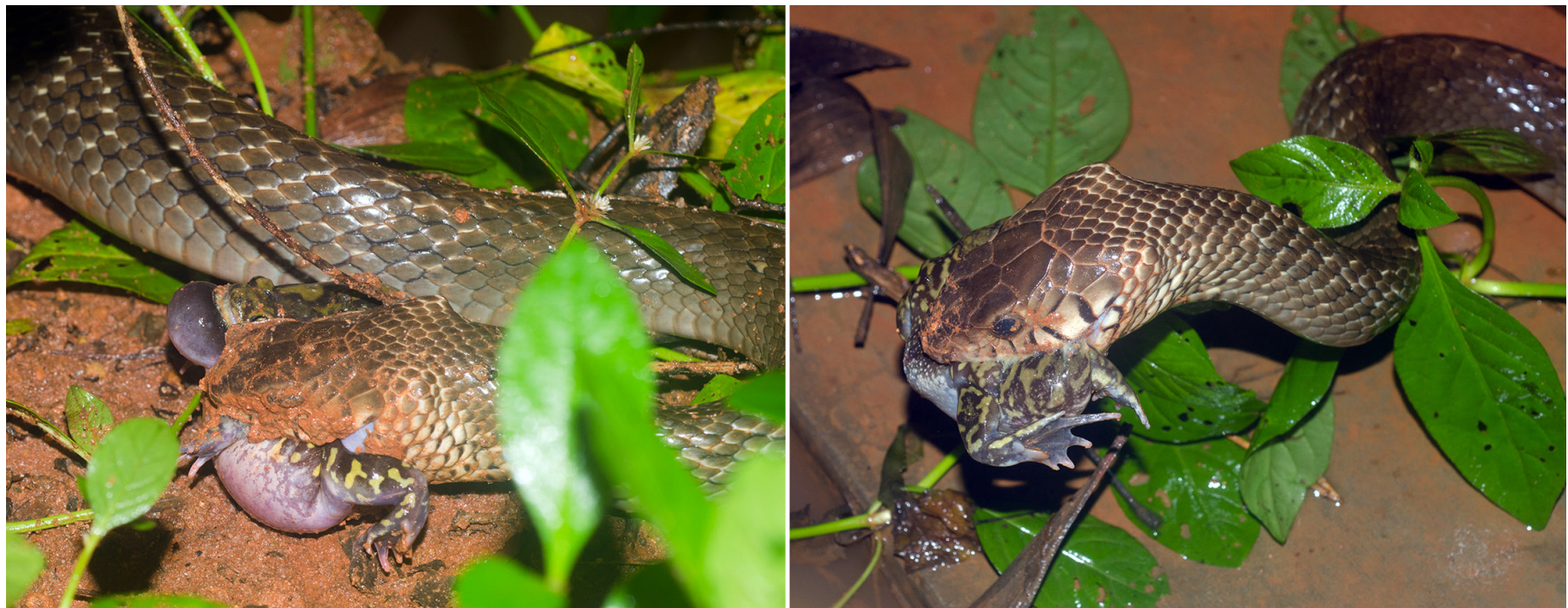

Fig. 1. An adult Indian Ratsnake (Ptyas mucosa) grasping (left) and ingesting (right) two different male Marbled Balloon Frogs (Uperodon systoma) on the Pondicherry University Campus, Puducherry, India. Photographs (ZRC(IMG) 2.488-2.489) by Avrajjal Ghosh. 
fishes, and other reptiles, including conspecifics (Whitaker and Captain 2004; Saha and Chaudhuri 2017).

At 2355 h on 4 October 2018, after a heavy rainfall, we encountered an adult Indian Ratsnake (Fig. 1) grasping a male Marbled Balloon Frog (Uperodon systoma) adjacent to a water-filled ditch in a small patch of forest dominated by Mangium (Acacia mangium) and Neem (Azadirachta indica). The snake's head was covered almost entirely by wet red soil mixed with skin secretions of the frog. The frog had inflated itself to resist being swallowed. This is a typical adaptive defensive behavior commonly seen in frogs of the genus Uperodon (Jena and Palita, 2019). The snake pushed the frog against its body to facilitate ingestion. After about $10 \mathrm{~min}-$ utes, the snake had fully ingested the frog. After rubbing its head against the ground to remove excess soil from its face, it entered the water-filled ditch where a number of Marbled Balloon Frogs and Indian Painted Frogs (U. taprobanicus) were calling. It grabbed another male U. systoma, carried the frog out of the ditch, and devoured it headfirst (Fig. 1). This lasted 8 minutes, after which the snake moved out of sight.

Diel activity shifts in snakes are linked predominantly to ectothermy (Oishi et al. 2004; Sperry et al. 2010). Reasons other than or in addition to temperature regulation include alignment of activity with that of their prey (Marques and Puorto 1998) or avoiding diurnal predators (Dorcas and Peterson 1998). Other studies attribute the plasticity in shifting activity time to photoperiods (Ellis et al. 2006) and hormones (Lutterschmidt and Mason 2010). Unfortunately little is known about the foraging ecology of most snakes (DeGregorio et al. 2014) or their circadian rhythms (Oishi et al. 2004).

In the above-mentioned case we suggest that the reason for nocturnal activity was prey availability coupled with a seasonal effect. The southeastern coast of India receives the most rainfall during the retreating monsoon during October and November. This provides a short window for anurans to breed. Explosive breeders, including Uperodon systoma, $U$. taprobanicus, and toads in the genus Duttaphrynus, congregate in and around temporary bodies of water. Therefore, we assume that the reason for nocturnal activity of a primarily diurnal snake was to take advantage of the opportunity presented by the concentration of its prey.

\section{Acknowledgements}

We thank Dr. Chan Kin Onn, Curator of Herpetology, Lee Kong Chian Natural History Museum, National University of Singapore, for cataloging the images.

\section{Literature Cited}

Chaudhuri, A., A. Sardar, S. Chowdhury, and A. Dutta. 2018. Ptyas mucosa (Indian Ratsnake). Diet and Behavior. Herpetological Review 49: 352-353.

Das, I. 2010. A Field Guide to the Reptiles of South-East Asia. New Holland Publishers (UK) Ltd., London, United Kingdom.

DeGregorio, B.A., J.H. Sperry, D.P. Valente, and P.J. Weatherhead. 2014. Facultative nocturnal behaviour in snakes: experimental examination of why and how with ratsnakes (Elaphe obsoleta) and racers (Coluber constrictor). Canadian Journal of Zoology 92: 229-237.

Dissanayake, D.S.B. and S. Wellappuliarachchi. 2016. Amphiesma stolatum (Buffstriped Keelback) Diet. Herpetological Review 47: 307.

Dorcas, M.E. and C.R. Peterson. 1998. Daily body temperature variation in freeranging Rubber Boas. Herpetologica 54: 88-103.

Dutta, A., S. Chowdhury, and A. Chaudhuri. 2017. Nocturnal foraging by Buffstriped Keelbacks, Amphiesma stolatum (Linnaeus 1758) (Reptilia: Squamata: Natricidae). Reptiles \& Amphibians 24: 175-176.

Ellis, D.J., B.T. Firth, and I. Belan. 2006. Circadian rhythm of behavioral thermoregulation in the sleepy lizard (Tiliqua rugosa). Herpetologica 62: 259-265.

Jena, S.C. and S.K. Palita. 2019. Habitat choice and arboreal behaviour of Sri Lankan narrow mouthed frog Uperodon taprobanicus (Parker, 1934) in mangroves of Bhitarkanika, Odisha, east coast of India. Proceedings of the Zoological Society 73: 99-107.

Lutterschmidt, D.I. and R.T. Mason. 2010. Temporally distinct effects of stress and corticosterone on diel melatonin rhythms of red-sided garter snakes (Thamnophis sirtalis). General and Comparative Endocrinology 169: 11-17.

Marques, O. and G. Puorto. 1998. Feeding, reproduction and growth in the crowned snake Tantilla melanocephala (Colubridae), from southeastern Brazil. Amphibia-Reptilia 19: 311-318.

Mebert, K., B. Trapp, G. Kreiner, H. Billing, J. Speybroeck, and M. Henggeler. 2011. Nocturnal activity in Natrix tessellata, a neglected aspect of its behavioral repetoire. Mertensiella 18: 234-236.

Metcalfe, N.B., N.H.C. Fraser, and M.D. Burns. 1998. State-dependent shifts between nocturnal and diurnal activity in salmon. Proceedings of the Royal Society B: Biological Sciences 265: 1503-1507.

Oishi, T., K. Nagai, Y. Harada, M. Naruse, M. Ohtani, E. Kawano, and S. Tamotsu. 2004. Circadian rhythms in amphibians and reptiles: Ecological implications. Biological Rhythm Research 35: 105-120.

Saha, A. and A. Chaudhuri. 2017. Ptyas mucosa (Indian Rat Snake). Diet/cannibalism. Herpetological Review 48: 681.

Sperry, J.H., G.B. Demers, G.L.F. Carfagno, and P.J. Weatherhead. 2010. Latitudinal variation in seasonal activity and mortality in ratsnakes (Elaphe obsoleta). Ecology 91: 1860-1866.

Sperry, J.H., M.P. Ward, and P.J. Weatherhead. 2013. Effects of temperature, moon phase, and prey on nocturnal activity in ratsnakes: An automated telemetry study. Journal of Herpetology 47: 105-111.

Whitaker, R. and A. Captain. 2004. Snakes of India. The Field Guide. Draco Books, Chennai, India. 